\title{
Tired of losing valuable data? Build your lab ecological database as a cornerstone for long-term approaches
}

\author{
Juan Alberti \& Octavio Massone \\ Instituto de Investigaciones Marinas y Costeras (IIMyC), FCEyN, UNMdP-CONICET.
}

\begin{abstract}
Aвstract. Long-term ecological data is essential to identify impacts of global change or to analyse the response of local systems to perturbations. Thus, ecologists are facing the compromise to collect and process longer-term data while specific funding for those purposes is extremely scarce. Although more funding to gather and store long term data would be ideal, it is unlikely to occur, at least in the short term. Another (most plausible) option could be to dive among the many spreadsheets belonging to one or more colleagues with shared variables and from several projects over the years. Obviously, this might be an extremely time-consuming and tedious task. To simplify this and save time, it would be ideal to store as much data as possible (individual or lab generated) in a single comprehensive database. Given that the process of building, maintaining and doing queries on such databases could be scary for ecologists not familiarized, here we provide a step-by-step guide to build 1) a generic and versatile ecological database, and 2) a graphical user interface to load, update, verify, view and download data. The scripts to build them are programmed on open-software (MariaDB and R), and we also provide instructions to change them according to many usual situations.
\end{abstract}

[Keywords: relational database, graphical user interface, shiny, step-by-step guide]

\begin{abstract}
Resumen. ¿Te cansaste de perder datos valiosos? Armá una base de datos ecológica como piedra fundacional para estudios a largo plazo. Los datos ecológicos a largo plazo son esenciales para identificar impactos del cambio global o para analizar la respuesta de ecosistemas locales a perturbaciones. Por lo tanto, los/as ecólogos/as se enfrentan al compromiso de recolectar y procesar datos a largo plazo mientras que los fondos específicos para estos fines son extremadamente escasos. Si bien sería ideal que hubiera mayor financiamiento para recolectar y almacenar datos a largo plazo, es poco probable que esto vaya a suceder, al menos en el corto plazo. Otra opción (más realista) podría ser la de bucear en las múltiples libretas y archivos propios y de colegas en busca de variables compartidas a lo largo del tiempo. Esto obviamente requiere de mucho tiempo y dedicación. Para simplificar esta tarea y ahorrar algo de tiempo, sería ideal poder almacenar tantos datos como fuera posible (propios o del laboratorio) en una base de datos única y completa. Dado que el proceso de armado y mantenimiento de bases de datos, junto con las consultas pertinentes, puede sonar atemorizador para ecólogas/os no familiarizadas/os, acá proponemos una guía paso a paso para crear 1) una base de datos ecológica genérica y versátil, y 2) una interfaz gráfica para cargar, actualizar, verificar, visualizar y descargar datos de dicha base. Los comandos para crearlas fueron programados en software libre (MariaDB y R) y también proveemos instrucciones para cambiarlos de acuerdo a varias situaciones comunes.
\end{abstract}

[Palabras clave: base de datos relacional, interfaz gráfica de usuario, shiny, guía paso a paso]

\section{INTRODUCTION}

Over the last 50 years, anthropogenic impacts have been affecting ecosystems at rates unprecedented in recorded history (Venter et al. 2016). Moreover, those changes are extending beyond natural systems, having increasingly negative feedbacks on human well-being (Millennium Ecosystem Assessment Panel 2005). However, realizing this scenario is difficult because many of those direct and indirect effects have a slow accumulation rate and often become evident after decades (Reich et al. 2012; Komatsu et al. 2019). In this context, long-term studies become essential, but unfortunately their funding and frequency are both decreasing (Silvertown et al. 2010; Hughes et al. 2017).

Editor asociado: Guillermo Martínez Pastur $\bar{\triangle}$ juanalberti@gmail.com
Ecologists have been aware of the benefits of long-term studies for decades, not only for academic reasons, but also for policy and decision-making in public and private environments (Callahan 1984; Bakker et al. 1996; Hughes et al. 2017). Among the merits of long-term studies we can count: 1) quantifying ecological responses to drivers of ecosystem change, 2) understanding complex ecosystem processes that occur over prolonged periods, 3) providing core ecological data that may be used to develop theoretical ecological models and to parameterize and validate simulation models, 4) acting as platforms for collaborative studies, thus promoting multidisciplinary research, 5) answering questions not yet imagined, and 6) providing data and understanding scales relevant to management, and hence

Recibido: 3 de Junio de 2021

Aceptado: 7 de Noviembre de 2021 
critically supporting evidence-based policy, decision-making, and the management of ecosystems (Magurran et al. 2010; Lindenmayer et al. 2012). Due to the intrinsic value of these long-term studies, most of them are published in high impact journals, and they disproportionately contribute to reports written to inform environmental policy and decision-making (Hughes et al. 2017). Long-term data are essential to determine how resilient to anthropogenic change are ecosystems (Silvertown et al. 2010). Indeed, studies based on temporally extended data are the only way to detect the impact of cumulative slow-acting or infrequent disturbances (Turner et al. 2003). This is not anecdotal, given that understanding the underlying mechanisms of ecosystem functioning is the best insurance to guarantee the long-term persistence of ecosystems (Bakker et al. 1996).

In addition, to fully comprehend the mechanisms leading to changes in community and ecosystem functioning, it is important to backup long-term monitoring with experiments (Silvertown et al. 2010). As a paradigmatic example, the Park Grass Experiment (located in southern England and started in 1856) is the longest ongoing experiment, it was conceived to understand the effects of fertilizers in grasslands, and it was useful to answer questions ranging from local adaptation to community responses to climatic perturbations (Silvertown et al. 2006). Indeed, experiments have been frequently performed to understand how global change drivers are affecting community structure and ecosystem functioning (Komatsu et al. 2019). These factors include climate change, habitat destruction, alteration of nutrient cycles, overexploitation and species invasions (Millennium Ecosystem Assessment Panel 2005). To predict human inputs in future scenarios and to detect potential feedback (Smith et al. 2009), several studies have explored how natural systems respond to global change (Song et al. 2019). However, our ability to predict those effects is still strongly limited, in part because of the common context dependency (on the environment and the study site) of the experimental results (Komatsu et al. 2019), and also due to the lack of long-term series that allow the detection of slow or baseline changes.

It is clear that long-term monitoring and experiments are highly desirable and valuable. Indeed, the longer the time series, the more valuable it becomes, and the reasons to continue feeding it also increase (Silvertown et al.
2010). However, their persistence in time not only requires funding, but their data are also more difficult to handle and to store (Mills et al. 2015; Hughes et al. 2017). The awareness of scientists on the benefits of comprehensive databases led to extraordinary initiatives, being GBIF (www.gbif.org) a paradigmatic example. However, global databases generally store a subset of all the variables measured during local research programs and rarely include experiments (i.e., biodiversity: GBIF; taxonomy: ITIS, occurrences: iNaturalist; DNA-based species identification: BOLD). Not surprisingly, a considerable amount of GBIF data comes from lab or institutional initiatives likely not designed for that purpose. Thus, there is still a need to relate and store locally generated data. Unfortunately, it is unlikely that more funding to gather and store long-term data would be the norm in the near future. A most plausible alternative could be to dive among the many spreadsheets belonging to one or more colleagues with shared variables and from several projects over the years. To simplify this and save time, it would be ideal to store as much data as possible (individual or lab generated) in a single comprehensive database. In order to reduce the complexity of dealing with these data, a few guidelines have been proposed, including 1) the use of standardized metadata that facilitates the integration of different sources of data, 2) the promotion collaboration between potential users, 3 ) the use of embargo for sensitive data, and 4) the storage of data in institutional reliable databases (Mills et al. 2015). However, following these guidelines could be extremely time-consuming, and requires programming knowledge usually not common in ecology labs. Here we provide a compendium of scripts ( $>3500$ lines in total) to a) simplify the creation of a versatile database likely suitable for most ecological studies, b) along with graphical user interface (GUI) to facilitate the insertion, update and deletion of data onto that database. In addition, c) we provide a step-by-step guide to ease the implementation of a fully working database + GUI, as well as d) a series of spreadsheets with fake data to illustrate how data should be organized.

\section{Materials and Methods}

\section{Database description}

We designed a relational database that we hope is sufficiently versatile to be useful for a variety of ecological and related studies. This database was created in MariaDB and 
basically consists of 18 tables that store different sources of data and the instructions of how they relate to each other (full diagram can be seen in Supplementary Material, Appendix S1). The core of the database can be summarized in five groups of tables: the information of experiments (or samplings), spatial scales, dependent variables (data), insertions, and values (registry), which depend on all other groups (registry) (Figure 1). Each table contains a column with values that are the unique identifiers of each row and columns for the data that we want to store (which obviously varies between tables). Some tables also have foreign keys, that are columns with the unique identifiers of other tables and that are the way to link the information from different tables.

As an example of the utility of foreign keys, there is a table named 'experimento' which is designed to store general information (e.g., name, description, date) of a given study (we named it 'experimento', but it could store information of an experiment or sampling event). There is another table named 'usuarios' which stores data from the user responsible for one or more studies (i.e., name). The study is linked to a given user with the foreign key of 'usuarios' in the 'experimento' table. One could ask here why not to store everything on the same table, and the reason is that the same user can be responsible for several studies, and it is not useful to repeat the user information each time. Moreover, as the database increases, having all data in the same table would require as many columns as variables have been explored, which will rapidly lead to an enormous and impossible-to-use table.

Briefly, the remaining tables store a variety of data that can be organized in two large groups, generalities and value-related. The first and largest group includes the following tables: the type of study ('tipo_experimento'; i.e., observational or experimental), explanatory variables ('factor'; i.e., grouping or manipulated variables; e.g., nutrient

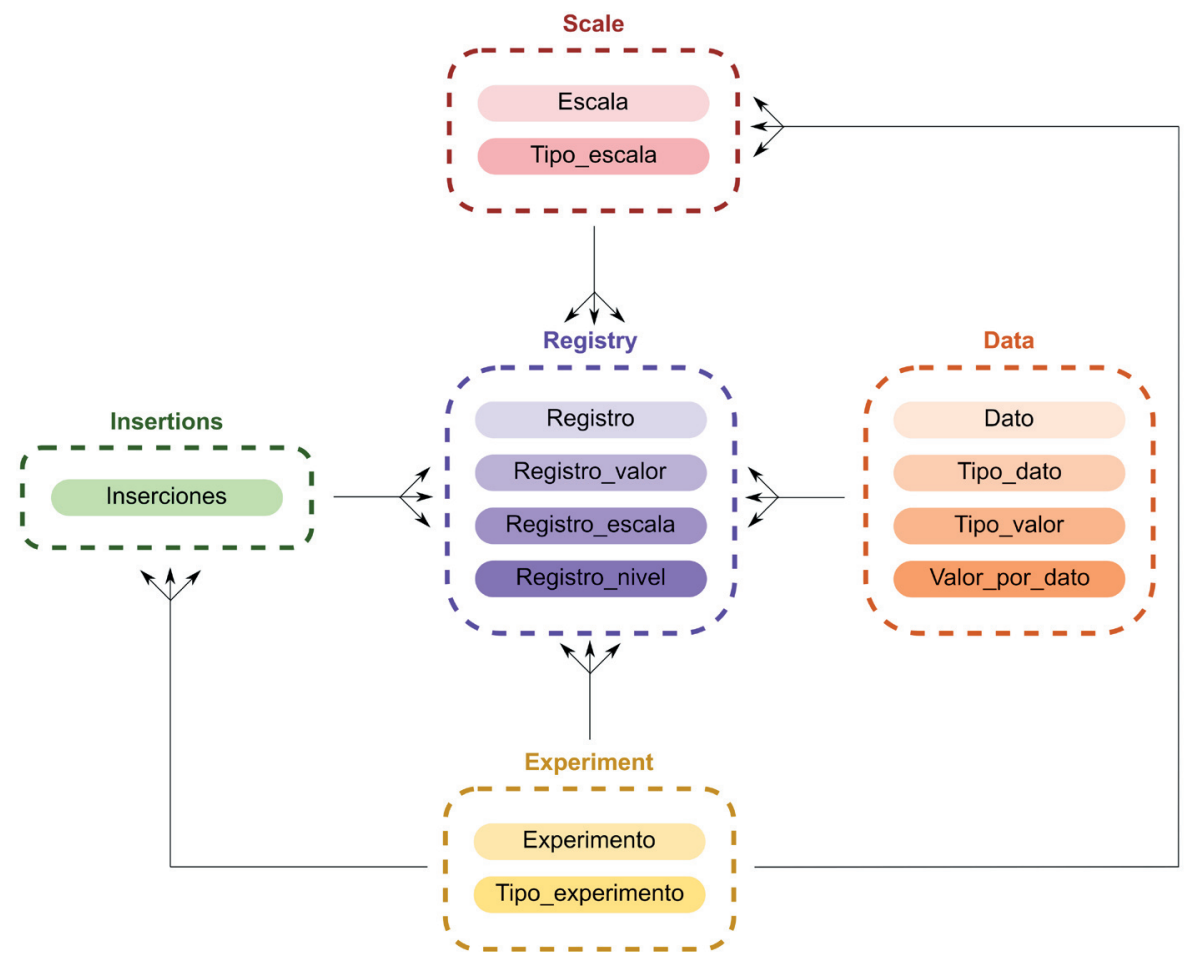

Figure 1. Schematic representation of the database's core structure. Black texts with colored background are the names of the most relevant tables. We grouped (dashed boxes) these tables according to their content, summarized by the concept in colored text above each box. Arrows denote connected tables, and they are multi-headed to highlight that a given value from the origin of the arrow could be repeated several times at its end.

Figura 1. Representación esquemática de la estructura principal de la base de datos. Los textos en negro con fondo de colores representan los nombres de las tablas más importantes. Agrupamos a estas tablas (usando cajas de bordes cortados) en función de su contenido, que se resume con el concepto que está en color sobre cada caja. Las flechas denotan tablas que están conectadas, y usamos flechas con tres puntas para resaltar que un mismo valor de una tabla que está en el inicio de la flecha puede aparecer varias veces en las tablas que están al final de la flecha. 
addition), the levels that those variables have ('nivel'; i.e., experimental treatments or sampling conditions; e.g., high, low, control), the spatial sampling or experimental design (i.e., 'tipo_escala'; e.g., block, plot, subplot, subsubplot; there is a very important issue regarding the functioning of this table, don't forget to read the section 'limitations'), the levels of those scales ('escala'; i.e., label of each scale on a given experiment, as well as the latitude and longitude where the largest scales are located; e.g., block A, plot 2), data types ('tipo_dato'; i.e., any term that broadly groups data values in a useful way for the users; e.g., kingdom for living beings, chemical or physical for the abiotic environment), the type of dependent variable ('tipo_valor'; i.e., a term that groups dependent variables, as well as their units of measure; e.g., biomass, cover, count), a table that links the last two tables ('valor_por_dato'; i.e., for which data type a given type of dependent variable could be used; e.g., biomass could be used for living beings but not for the chemical environment), dependent variables ('dato'; i.e., which species or abiotic variable were measured; e.g., Sporobolus rigens $[$ data type $=$ Plantae, type of dependent variable $=$ cover in $\%]$, total organic carbon [data type $=$ chemical environment, type of dependent variable $=$ concentration in $\left.\mathrm{mg} \mathrm{cm}^{-3}\right]$ ), the locality ('ciudad') (i.e., name, longitude and latitude), and system ('ambiente') (i.e., name; e.g., grassland).

Finally, the value-related group includes tables that link the information above with the observed values: the general information is merged in a register table ('registro'; i.e., locality, study, date, system), a table that links register to scales tables for a given observation ('registro_escala'), a table that links register to factor level tables ('registro_nivel'), the table where values are stored, which is linked to the register type of dependent variable and dependent variable tables ('registro_valor'), and, finally, a table that keeps track of insertion events to be able to roll them back in case of detected errors ('inserciones').

\section{Limitations}

The database was designed trying to maximize its flexibility (allowing the user to include as many factors, scales and dependent variables as needed) while making the process relatively simple. However, it has limitations that require quite some attention and commitment from the user before uploading data. As a general note, the files used to insert data can't have annotations, comments, figures, the first column should contain variable names, there should be no empty rows between data (see cover.ods, lice.xlsx, subregistries.xlsx, or long_format.xls in tinyurl.com/rd84jt2k for examples).

Moreover, the scripts provided to build the database have some pre-inserted values in some tables. Those values are needed to improve the functionality of the GUI (see next section) and facilitate the insertion of data. Two study types are pre-defined (observational and experimental); if additional study types are needed, they should be added manually (e.g., using MySQL Workbench; see last section). Similarly, Plantae, Animalia, Fungi and Bacteria (given that there is no clear consensus on the number and definition of the remaining kingdoms) are pre-defined data types (as they will likely not vary). In addition, four spatial scale values are included: Block, Plot, SubPlot, SubSubPlot. It is very important to keep in mind that they are intended to represent the spatial dependence between them (a SubSubPlot is nested in a SubPlot, that is nested in a Plot that is ultimately nested in a Block), rather than a true spatial design with blocks, plots, etc. Block is supposed to apply to the largest scale in a given study, regardless of the true spatial design of that study. For example, let's imagine that you conducted a study to estimate the number of lice in the heads of your colleagues, and to achieve this you randomly sampled five $1 \times 1$ $\mathrm{cm}$ squares in each head. Thus, the names of your colleagues should be introduced in the Block column because heads are the largest spatial unit sampled, and the $1 \mathrm{~cm}^{2}$ quadrats should be stored in the Plot column because quadrats were nested in heads. Now let's imagine that you perform an experiment to evaluate the impact of ecologists in natural grasslands by doing two repetitions of paired control-exclosure units (usually referred as blocks) in three different countries. In this example, countries (the largest spatial unit) would be introduced in the Block column, while true blocks should be introduced in the Plot column. If the user does not follow this organization, the insertion process will invariably fail.

Given that the organization of living beings is based on a complex structure, inserting all these data manually can be very tedious. To simplify this task, we included the 
possibility to upload this information using a complementary file (for a template, see taxa.xls in tinyurl.com/rd84jt2k). However, to make it work, the structure of this file (i.e., column names) could not be modified, unless the code of the server.R file in the alta_deps folder is modified accordingly.

When adding a new study to the database, some fields should be added before others. Given that there are several dependencies, we structured the GUI to present the first six options on the lateral panel (the ones needed to insert all the data of a study) in the order that they should be introduced. If data is not introduced in this order, the insertion process will likely fail. Similarly, if after some time the user finds out that a given study needs to be removed, the user should first delete the insertion event and then the study. That is why the seventh and eighth elements of the lateral panel are shown in that order.

Due to the internal calculations to make the GUI responsive and user-friendly, it is very important that the input files have the scales ordered in columns, from higher to lower, and without other columns interspersed between them. Similarly, when supplying data in the wide format, the columns containing all dependent variables should be together and placed at the end of the file (i.e., with no other columns with data after or between them). We finish this section with a reminder that could be considered a limitation for some: bear in mind that $\mathrm{R}$ is case-sensitive and thus, users should consistently name factors, levels, scales, etc. Not taking this into account will lead to many headaches.

\section{Integration with other databases}

At this time you might be thinking that it is just another ecological database. Although you would probably be right, we conceived it as a first approach (hopefully collaborative in the near future) towards a versatile database designed to ease the integration of personal or lab generated data. We believe that its open source nature will grant this, and eventually ease the integration with popular global/ national databases. In this regard, the current formulation includes nearly all data needed to feed GBIF sampling-event data (tinyurl.com/ mrxm5yee), eBird records (tinyurl.com/ 4 scmy2d4), or iNaturalist observations (tinyurl.com/2y2d36ee), although with different variable names in all cases, which will require manual intervention. For other databases such as BOLD, there is only partial match with the required data in the current form of the proposed database (tinyurl.com/ 2 p99s4fw), although it could be easily adapted to include missing variables. In other words, there is no perfect match with bulk upload templates of any known global database. However, this could be achieved with minimal (column name changes) to moderate additions (new variables and data types). We hope that future collaborations will produce the necessary changes to increase the versatility, usefulness, and integration of this database. Importing from external sources like those databases is much easier (using a spreadsheet), just keep reading. Unfortunately, the current implementation of the database+GUI does not allow connections to external APIs (yet).

\section{Graphical user interface}

To simplify the process of insertions and deletions into the database, we designed a GUI in $R$ ( $R$ Core Team 2021) using the shiny package (Chang et al. 2020) and several add-ons. Due to space limitations, and given that the GUI is not necessary (although highly recommended), we placed a description of the GUI in Supplementary Material, Appendix S2.

\section{The files}

All the files we describe in this article can be found in a GitHub repository: tinyurl.com/ 2sukvfzj. There are ten folders containing the $R$ scripts for each of the nine options of the lateral panel, as well as the welcome screen. In addition, there are two other folders: one containing the SQL script to build the database (sql) as well as sample files; the other containing screenshots. Sample files and screenshots are used in Supplementary Material, Appendix S3. Each sample file has two sheets. The first sheet contains fake data to illustrate each of the capabilities of the database + GUI, while the second sheet contains a description of the first sheet. Finally, unsorted on the root folder there are some other files useful for working remotely (.htaccess and .htpasswd). These files should be edited upon user needs if a password is required to access the GUI (not needed when using the virtual hard disk; see below). Two other useful files are also located here: index.html (whose text can be edited but the link is needed for the proper functionality of the GUI), and utils.R (a group of $R$ functions that are essential for the GUI). Note that it is essential to preserve the relative location of utils.R to the R scripts folders. We included 
comments in all scripts to explain almost all commands. We hope that these explanations would be useful if the GUI or database need to be adapted according to user needs.

\section{Step-by-step guide}

In this section we provide a brief but comprehensive description of the steps needed to create the database and make use of the functionality of the GUI. However, we must warn you that Shiny Server only runs under Linux operating systems (see Supplementary Material, Appendix S4 for installation instructions). Nevertheless, there is a solution for those that still resist to embrace the joy and happiness of using Linux. For those that prefer simpler things, we created a virtual hard disk containing a Debian Linux distribution (user: ecology; password: ecologylab, likely not needed) with MySQL Workbench (the connection to the database, named 'Ecology $\mathrm{lab}^{\prime}$ is configured, but in case needed, MariaDB user and password are the same as for Debian), Shiny Server, $\mathrm{R}$, the required packages and $\mathrm{R}$ Studio installed and configured. The required steps are: 1) download the virtual hard disk (bit.ly/34FMAkq), 2) download VirtualBox (tinyurl.com/2p8d8pzy) and install it, 3) import the virtual hard disk (Debian.ova) into VirtualBox (File -> Import), 4) try to launch Debian (double click) from the lateral menu. After this, VirtualBox will complain about a network error (see Supplementary
Material, Appendix S5). Press the button to change network preferences. A new window with 'Network' selected on the lateral panel should pop-up. Just press 'OK'. That should fix this issue, 5) now start Debian (this time it should work), 5a) open 'Firefox ESR'. [Don't complain about Linux's appearance, we didn't tweak anything to keep it simple and lightweight, but be aware that it could be incredibly astonishing.]. Once in Firefox, there is a bookmark on the upper left corner that redirects to the GUI (or type 'localhost: $3838^{\prime}$ on the address bar [without quotes]), 5b) alternatively, users can also double click on ' $\mathrm{IP}^{\prime}$. This will open a terminal with an IP number (i.e., four groups of numbers separated by dots; e.g., 192.168.0.26). Users can then type those numbers followed by ':3838' on the address bar of any internet browser on the same computer (i.e., 192.168.0.26:3838). In case needed (likely not in early stages of using the database), there is a shortcut for MySQL Workbench in the desktop.

A guide to use the GUI is available in Supplementary Material, Appendix S3. After reading it, you should be ready to go. That's all Folks! May the force be with you ;-)

Acknowledgements. We want to thank Diego Navarro for useful suggestions to improve the GUI and Pedro Daleo and Matías Merlo for their valuable comments on earlier versions of this manuscript.

\section{REFERENCES}

Bakker, J. P., H. Olff, J. H. Willems, and M. Zobel. 1996. Why do we need permanent plots in the study of long-term vegetation dynamics? Journal of Vegetation Science 7:147-156. https://doi.org/10.2307/3236314.

Callahan, J. T. 1984. Long-Term Ecological Research. BioScience 34:363-367. https://doi.org/10.2307/1309727.

Chang, W., J. Cheng, J. Allaire, Y. Xie, and J. McPherson. 2020. shiny: web application framework for R.

Dirzo, R., H. S. Young, M. Galetti, G. Ceballos, N. J. B. Isaac, and B. Collen. 2014. Defaunation in the Anthropocene. Science 345:401-406. https://doi.org/10.1126/science.1251817.

Estes, J. A., J. Terborgh, J. S. Brashares, M. E. Power, J. Berger, W. J. Bond, S. R. Carpenter, T. E. Essington, R. D. Holt, J. B. C. Jackson, R. J. Marquis, L. Oksanen, T. Oksanen, R. T. Paine, E. K. Pikitch, W. J. Ripple, S. A. Sandin, M. Scheffer, T. W. Schoener, J. B. Shurin, A. R. E. Sinclair, M. E. Soulé, R. Virtanen, and D. A. Wardle. 2011. Trophic downgrading of planet earth. Science 333:301-306. https://doi.org/10.1126/science.1205106.

Hughes, B. B., R. Beas-Luna, A. K. Barner, K. Brewitt, D. R. Brumbaugh, E. B. Cerny-Chipman, S. L. Close, K. E. Coblentz, D. Nesnera, K. L, S. T. Drobnitch, J. D. Figurski, B. Focht, M. Friedman, J. Freiwald, K. K. Heady, W. N. Heady, A. Hettinger, A. Johnson, K. A. Karr, B. Mahoney, M. M. Moritsch, A.-M. K. Osterback, J. Reimer, J. Robinson, T. Rohrer, J. M. Rose, M. Sabal, L. M. Segui, C. Shen, J. Sullivan, R. Zuercher, P. T. Raimondi, B. A. Menge, K. Grorud-Colvert, M. Novak, and M. H. Carr. 2017. Long-term studies contribute disproportionately to ecology and policy. BioScience 67:271-281. https://doi.org/10.1093/biosci/biw185.

Jackson, J. B. C., M. X. Kirby, W. H. Berger, K. A. Bjorndal, L. W. Botsford, B. J. Bourque, R. H. Bradbury, R. Cooke, J. Erlandson, J. A. Estes, T. P. Hughes, S. Kidwell, C. B. Lange, H. S. Lenihan, J. M. Pandolfi, C. H. Peterson, R. S. Steneck, M. J. Tegner, and R. R. Warner. 2001. Historical overfishing and the recent collapse of coastal ecosystems. Science 293:629-637. https://doi.org/10.1126/science.1059199.

Komatsu, K. J., M. L. Avolio, N. P. Lemoine, F. Isbell, E. Grman, G. R. Houseman, S. E. Koerner, D. S. Johnson, K. R. Wilcox, J. M. Alatalo, J. P. Anderson, R. Aerts, S. G. Baer, A. H. Baldwin, J. Bates, C. Beierkuhnlein, R. T. Belote, J. Blair, J. M. G. Bloor, P. J. Bohlen, E. W. Bork, E. H. Boughton, W. D. Bowman, A. J. Britton, J. F. Cahill, E. Chaneton, N. R. Chiariello, J. Cheng, S. L. Collins, J. H. C. Cornelissen, G. Du, A. Eskelinen, J. Firn, B. Foster, L. Gough, K. 
Gross, L. M. Hallett, X. Han, H. Harmens, M. J. Hovenden, A. Jagerbrand, A. Jentsch, C. Kern, K. Klanderud, A. K. Knapp, J. Kreyling, W. Li, Y. Luo, R. L. McCulley, J. R. McLaren, J. P. Megonigal, J. W. Morgan, V. Onipchenko, S. C. Pennings, J. S. Prevéy, J. N. Price, P. B. Reich, C. H. Robinson, F. L. Russell, O. E. Sala, E. W. Seabloom, M. D. Smith, N. A. Soudzilovskaia, L. Souza, K. Suding, K. B. Suttle, T. Svejcar, D. Tilman, P. Tognetti, R. Turkington, S. White, Z. Xu, L. Yahdjian, Q. Yu, P. Zhang, and Y. Zhang. 2019. Global change effects on plant communities are magnified by time and the number of global change factors imposed. Proceedings of the National Academy of Sciences 116: 17867-17873. https://doi.org/10.1073/pnas.1819027116.

Lindenmayer, D. B., G. E. Likens, A. Andersen, D. Bowman, C. M. Bull, E. Burns, C. R. Dickman, A. A. Hoffmann, D. A. Keith, M. J. Liddell, A. J. Lowe, D. J. Metcalfe, S. R. Phinn, J. Russell-Smith, N. Thurgate, and G. M. Wardle. 2012. Value of long-term ecological studies. Austral Ecology 37:745-757. https://doi.org/10.1111/j.1442-9993.2011.02351.x.

Magurran, A. E., S. R. Baillie, S. T. Buckland, J. M. Dick, D. A. Elston, E. M. Scott, R. I. Smith, P. J. Somerfield, and A. D. Watt. 2010. Long-term datasets in biodiversity research and monitoring: assessing change in ecological communities through time. Trends in Ecology and Evolution 25:574-582. https://doi.org/10.1016/j.tree.2010.06.016.

Millennium Ecosystem Assessment Panel. 2005. Ecosystems and human well-being: synthesis. Island Press, Washington, U.S.A.

Mills, J. A., C. Teplitsky, B. Arroyo, A. Charmantier, Peter. H. Becker, T. R. Birkhead, P. Bize, D. T. Blumstein, C. Bonenfant, S. Boutin, A. Bushuev, E. Cam, A. Cockburn, S. D. Côté, J. C. Coulson, F. Daunt, N. J. Dingemanse, B. Doligez, H. Drummond, R. H. M. Espie, M. Festa-Bianchet, F. Frentiu, J. W. Fitzpatrick, R. W. Furness, D. Garant, G. Gauthier, P. R. Grant, M. Griesser, L. Gustafsson, B. Hansson, M. P. Harris, F. Jiguet, P. Kjellander, E. Korpimäki, C. J. Krebs, L. Lens, J. D. C. Linnell, M. Low, A. McAdam, A. Margalida, J. Merilä, A. P. Møller, S. Nakagawa, J.-Å. Nilsson, I. C. T. Nisbet, A. J. van Noordwijk, D. Oro, T. Pärt, F. Pelletier, J. Potti, B. Pujol, D. Réale, R. F. Rockwell, Y. Ropert-Coudert, A. Roulin, J. S. Sedinger, J. E. Swenson, C. Thébaud, M. E. Visser, S. Wanless, D. F. Westneat, A. J. Wilson, and A. Zedrosser. 2015. Archiving primary data: solutions for long-term studies. Trends in Ecology and Evolution 30:581-589. https://doi.org/10.1016/j.tree.2015.07.006.

R Core Team. 2021. R: a language and environment for statistical computing. R Foundation for Statistical Computing, Vienna, Austria.

Reich, P. B., D. Tilman, F. Isbell, K. Mueller, S. E. Hobbie, D. F. B. Flynn, and N. Eisenhauer. 2012. Impacts of biodiversity loss escalate through time as redundancy fades. Science 336:589-592. https://doi.org/10.1126/science.1217909.

Silvertown, J., P. R. Poulton, A. E. Johnston, G. Edwards, M. Heard, and P. M. Biss. 2006. The Park Grass Experiment 18562006: its contribution to ecology. Journal of Ecology 94:801-814. https://doi.org/10.1111/j.1365-2745.2006.01145.x.

Silvertown, J., J. Tallowin, C. Stevens, S. A. Power, V. Morgan, B. Emmett, A. Hester, P. J. Grime, M. Morecroft, R. Buxton, P. Poulton, R. Jinks, and R. Bardgett. 2010. Environmental myopia: a diagnosis and a remedy. Trends in Ecology and Evolution 25:556-561. https://doi.org/10.1016/j.tree.2010.06.015.

Smith, J. B., S. H. Schneider, M. Oppenheimer, G. W. Yohe, W. Hare, M. D. Mastrandrea, A. Patwardhan, I. Burton, J. Corfee-Morlot, C. H. D. Magadza, H.-M. Füssel, A. B. Pittock, A. Rahman, A. Suarez, and J.-P. van Ypersele. 2009. Assessing dangerous climate change through an update of the Intergovernmental Panel on Climate Change (IPCC) 'reasons for concern.' Proceedings of the National Academy of Sciences 106:4133. https://doi.org/10.1073/ pnas.0812355106.

Song, J., S. Wan, S. Piao, A. K. Knapp, A. T. Classen, S. Vicca, P. Ciais, M. J. Hovenden, S. Leuzinger, C. Beier, P. Kardol, J. Xia, Q. Liu, J. Ru, Z. Zhou, Y. Luo, D. Guo, J. Adam Langley, J. Zscheischler, J. S. Dukes, J. Tang, J. Chen, K. S. Hofmockel, L. M. Kueppers, L. Rustad, L. Liu, M. D. Smith, P. H. Templer, R. Quinn Thomas, R. J. Norby, R. P. Phillips, S. Niu, S. Fatichi, Y. Wang, P. Shao, H. Han, D. Wang, L. Lei, J. Wang, X. Li, Q. Zhang, X. Li, F. Su, B. Liu, F. Yang, G. Ma, G. Li, Y. Liu, Y. Liu, Z. Yang, K. Zhang, Y. Miao, M. Hu, C. Yan, A. Zhang, M. Zhong, Y. Hui, Y. Li, and M. Zheng. 2019. A meta-analysis of 1,119 manipulative experiments on terrestrial carbon-cycling responses to global change. Nature Ecology and Evolution 3:1309-1320. https://doi.org/10.1038/s41559-019-0958-3.

Turner, M. G., S. L. Collins, A. L. Lugo, J. J. Magnuson, T. S. Rupp, and F. J. Swanson. 2003. Disturbance dynamics and ecological response: the contribution of long-term ecological research. BioScience 53:46-56. https://doi.org/10.1641/ 0006-3568(2003)053[0046:DDAERT]2.0.CO;2.

Venter, O., E. W. Sanderson, A. Magrach, J. R. Allan, J. Beher, K. R. Jones, H. P. Possingham, W. F. Laurance, P. Wood, B. M. Fekete, M. A. Levy, and J. E. M. Watson. 2016. Sixteen years of change in the global terrestrial human footprint and implications for biodiversity conservation. Nature Communications 7:12558. https://doi.org/10.1038/ncomms12558.

Young, H. S., D. J. McCauley, M. Galetti, and R. Dirzo. 2016. Patterns, causes, and consequences of anthropocene defaunation. Annual Review of Ecology, Evolution and Systematics 47:333-358. https://doi.org/10.1146/annurevecolsys-112414-054142. 